\title{
Proposta para aproximações de uma história comparada das literaturas argentina e brasileira
}

\author{
Marcela Croce I UBA-Argentina
}

Resumo: A proposta de uma história comparada das literaturas argentina e brasileira como uma prática efetiva de integração regional, no marco de um Mercosul cujos aspetos culturais são relegados frente aos econômico-comerciais e às estratégias politicas para enfrentar como bloco às potencias mundiais, apresenta uma série de aspetos positivos que operam como incentivo para que seja posta em prática. Por um lado, promove o desenvolvimento de um comparatismo local, livre das limitaçôes que fomentam as literaturas comparadas como disciplina de origem metropolitana. Por outra parte, favorecem a elaboração de uma teoria e uma crítica literárias originais, retiradas "das ideias fora de lugar" que habitualmente se aplicam a tais propostas. Finalmente, ambicionam uma circulação cultural entre Argentina e Brasil que até agora permanece inédita e que se constitui mais em uma obrigação intelectual que em uma possibilidade desejável.

Palavras chave: Literaturas comparadas, história cultural, critica literária.

\section{Introdução}

A literatura brasileira foi isolada dos estudos comparados, cuja sistematização se depara com o conhecimento parcial e com a constante ansiedade 
pelo deleite proporcionado pelas "influências" europeias ou prestigiosas, que tentam dar conta de uma literatura latinoamericana. Por diversos motivos (entre eles o desconhecimento da língua portuguesa e a falta de bibliografia traduzida não são menos importantes, mesmo que também não sejam determinantes por causa da proximidade maior que se forja com literaturas escritas em línguas estrangeiras distantes da familiaridade imediata que preservam o espanhol e o português), nas universidades mais importantes da América de fala hispânica a literatura brasileira se estuda dentro da grade curricular e em relação direta com a literatura portuguesa. A língua e a articulação colônia/metrópole aparecem como pobre justificativa, metodicamente congregadas pelas universidades norteamericanas nas quais os departamentos de Literatura Espanhola e Portuguesa sujeitam os gentílicos ibéricos à abundante produção da América Latina.

Com o objetivo de pesquisar e, por conseguinte, rebater ou confirmar uma série de desencontros na história cultural da Argentina e do Brasil, a proposta que agora formulo convida à releitura da literatura gerada durante os séculos XIX e XX em ambos os países dentro de um contexto latino-americano. Um trabalho que se expresse por meio desta orientação não se satisfaz nas previsíveis caracterizações de "original" e de "necessário", mas solicita claramente a ampliação das possibilidades reais de intercâmbio e intervenção teórica, cultural, literária e editorial. O chamado a uma postulação literária, formulada a partir de nossos países, com disposição integradora e caráter performativo, tem a vontade de reverter tanto a inclinação imperial das teorias importadas como o condicionamento automático que geram no nosso meio intelectual, recaindo com muita frequência nesse sucedâneo da crítica que Roberto Schwarz estigmatizou, com um humor insidioso, como "ideias fora de lugar". 1

Exceto em alguns casos isolados ou em narrativa de fatos curiosos, os pontos de contato entre Argentina e Brasil não foram estudados em sua verdadeira relevância. Relegando a um segundo plano a inegável unidade cultural entre ambos os países originada inequivocamente pela colonização ibérica, deixando de lado que os movimentos literários e artísticos mundiais foram recebidos de forma similar e que a evolução histórico-social dos dois países seguiu um caminho semelhante, o marco que procuro desenhar nesta ocasião encontra sua melhor justificativa na necessidade de fortalecer um vínculo reiteradamente dilacerado por competições absurdas que resumem nos confrontos futebolísticos a intolerância mais rasa. A

1. SCHWARZ. As idéias fora do lugar. 
criação do Mercosul como projeto que, ao menos em seus postulados iniciais, aponta para uma integração que não se limite ao acordo alfandegário, reclama uma atenção peculiar dos aspetos culturais que ficaram desatendidos pelo enfoque quase exclusivo dos negócios comuns e das economias integradas.

Postular uma comunidade cultural impõe não apenas resgatar os pontos em comum entre iniciativas locais como também registrar o modo pelo qual os acontecimentos mundiais atuam sobre o Cone Sul. Por isso não é arbitrário começar a comparação por um fato que mudou o conceito continental e que estabeleceu uma modernização política irrevogável: a Revolução Francesa e, mais precisamente, a leitura local do fenômeno e a verificação de suas consequências mais palpáveis neste âmbito. De um lado, a mudança da Corte portuguesa para terras brasileiras; do outro, a Revolução de Maio. A continuidade do percurso, sem forçar analogias e atendo-se à cronologia latinoamericana, é provida pela evolução do romantismo como modelo estético e teórico para pensar a nação e a identidade, antes que as idiossincrasias locais, fomentadas pela balcanização continental, se expandissem em confrontos irredutíveis, como os que conduziram à Guerra do Paraguai na década de 1870. Próximo ao final do século XIX, sem que a união transitória e brutal que representou a Triple Aliança interviesse decisivamente em seu fomento, se comprovam aproximações intelectuais entre Argentina e Brasil. As influências do naturalismo francês nas letras locais, o destino de ambos os países depois da consolidação como Estados-Nação modernos, os centenários de 1910 e 1922, as vanguardas e a profissionalização da escrita; a literatura durante o varguismo e o peronismo, a possível releitura do fenômeno conhecido como boom da literatura latino-americana são outros momentos de coincidência cultural, ao menos relativos à manifestação de interesses comuns e à tendência de ajustar as literaturas locais ao processo proposto pelas literaturas europeias, de modo a assentar as bases do que a crítica designou como "sistema literário". ${ }^{2}$ A colaboração durante a última ditadura entre ambos os países e seus vizinhos (o funesto Plano Condor) e a resposta que o campo cultural, com variantes e extremismos, oferece a essa organização, representam os antecedentes mais manifestos - mesmo que evidentemente condenáveis em seu propósito de extermínio - dessa cooperação que com o Mercosul se transformaria em uma base de apoio para negociar como bloco regional o que a condição de países "do terceiro mundo" negava a seus integrantes.

2. CANDIDO. Formação da literatura brasileira. Momentos decisivos. 
Este desenvolvimento contempla, então, a produção literária e intelectual comparada da Argentina e do Brasil em relação a um contexto histórico, político e cultural mais amplo: América Latina e, em seguida, o Mercosul. Para levar a cabo a empresa seria requisito imprescindível a formação de um grupo de pesquisadores que contasse com integrantes de ambos os países e cujos progressos fossem publicados nas duas línguas, o que, além de favorecer uma fluência de comunicação, pode operar como uma espécie de controle preventivo sobre as arbitrariedades que costumam ser aplicadas quando se praticam "leituras do outro", além de gerar um novo espaço de discussão e intercâmbio de produção intelectual.

O esquema geral está orientado pelos objetivos os quais convém enumerar começando do que é mais imediato e viável até o que é mais pretensioso e ambicionado. Em primeiro lugar, a formação de um grupo de pesquisadores argentino-brasileiros que transforme em prática habitual e normativa o intercâmbio de conhecimentos, bibliografia, obras de referência e outras descobertas. Depois, deveriam concentrar os esforços para conseguir que esta comunidade investigativa intervenha diretamente na integração cultural através da publicação dos resultados, em princípio, parciais e tentativos, dos progressos obtidos no marco da investigação, garantindo a circulação bilíngue da informação. O estímulo à leitura de obras produzidas nos dois países permitiria ampliar o campo de atuação dos escritores, acadêmicos, críticos e intelectuais, afiançar a participação bilateral e, como propósito maior, sistematizar os estudos comparados para desenvolver uma futura Cátedra de Estudos Literários do Mercosul.

Se bem que os protocolos fundadores do bloco regional preveem a sanção de leis propensas à integração tanto político-econômica quanto cultural entre os países membros, boa parte dessa legislação - especialmente a que se refere à área cultural - não foi referendada pelos respectivos parlamentos. O momento histórico para promover os progressos neste campo é propício: nos últimos vinte anos ocorreu mais pela integração bilateral (desde a Declaração de Foz de Iguaçu, assinada por Raúl Alfonsín e José Sarney em 1985) que em toda a história moderna dos dois países, apesar de que sempre se pode buscar e encontrar antecedentes concretos ou ao menos atrativos esporádicos para o início de seu funcionamento. ${ }^{3}$ Entretanto, a integração cultural ainda é apenas uma expressão de desejo e permanece em uma condição hipotética. Uma história comparada das literaturas argentina e brasileira representa um pontapé inicial rumo a uma integração

3. FERNÁNDEZ BARAIBAR. Un solo impulso americano. El MERCOSUL de Perón. 
real neste aspecto e um ideal de trabalho pioneiro de referência para arrancar as ideias extraterritoriais e promover uma crítica, uma metodologia e um sistema independentes.

\section{Metodologia}

Como já havia dito, o método mais propício para encarar o trabalho é o das literaturas comparadas. Entretanto, convém estabelecer uma exceção, dado que esta disciplina funciona geralmente como a confirmação da superioridade de uma literatura "central" sobre outra "periférica". O comparatismo, longe de se despojar dos juízos de valor - o que seria ilógico e não contribuiria para uma crítica efetiva senão que levaria a mera descrição -, fomenta a dessimetria entre um texto "original" e aquele que se transforma em seu reflexo ou, com uma carga semântica mais virulenta, naquele sobre o qual o primeiro exerce sua influência. Rafael Gutiérrez Girardot foi o primeiro a alertar sobre o significado da "influência", em aparência um conceito neutro e em realidade a aplicação de uma categoria colonial. ${ }^{4}$ As literaturas comparadas, por outro lado, não se detêm na confrontação de dois textos, além das características de pioneirismo ou derivação que se lhes pretenda atribuir respectivamente, mas delineiam um terceiro termo que constitui o ideal de comparação, frente ao qual se prevê as abundâncias de uma parte e as deficiências da outra que, sob a aparência de uma objetividade sempre desejada nas atividades acadêmicas, justificam o exercício da comparação. Por sua vez, as cátedras de literaturas comparadas, como informa Edward Said, foram criadas ao final do século XIX, quando a consciência do império reclamava um conhecimento minucioso de suas colônias e daqueles territórios sobre os quais podia exercer sua hegemonia, estabelecendo uma comunidade cultural forjada no laboratório filológico - como fez Renan com a língua semítica ${ }^{5}$ - ou na academia para instalar uma proximidade que nivelava o caminho à ocupação e à invasão. ${ }^{6}$

Livres de tais exigências que se opõem, duas literaturas como a brasileira e a argentina podem se comparar sem apelar a esses duvidosos rigorismos e produzir um resultado muito mais produtivo. Para que o método comparativista

4. GUTIÉRREZ GIRARDOT. Modernismo. Supuestos históricos y culturales.

5. SAID. Orientalismo.

6. SAID. Cultura e imperialismo. 
não naufrague em imanências excessivas que poderiam conspirar contra a formulação de um sistema mais amplo que a obra de um autor ou as almejadas "grandes obras" de uma literatura, é adequado apelar ao respaldo histórico, formulando uma diacronia que se detém em sincronias compatíveis em que cada literatura registra um texto, um produtor, um modo de representação que proporciona a semelhança.

Certa deformação profissional faz com que os críticos e ensaístas pensem em termos de índices a formulação e o controle mais ajustado de suas hipóteses. Assim atuou Ángel Rama quando planejou uma série de exemplares lamentavelmente nunca realizados - que permitissem postular a literatura latinoamericana como um conjunto. ${ }^{7}$ Como uma série de temas que poderiam configurar os eventuais capítulos de uma historia comparada das literaturas, argentina e brasileira, regida pela história política e social, organizo estes enunciados que podem parecer ambiciosos, cujas hipóteses formuladas no mesmo esboço do plano talvez recorram com demasiada veemência à confrontação, mas que em realidade procuram encorajar uma empresa ajustada para que o Mercosul cultural comece seu caminho rumo à concretização.

\section{Primeiro momento}

Da independência à República oligárquica (1808-1810 a 1890)

Os antecedentes das literaturas nacionais podem ser traçados a partir da Carta de Pero Vaz de Caminha e a História e Descobrimento do Rio da Prata do alemão Ulrico Schmidl, por ocasião das aproximações a uma região que receberá em breve versão hiperbólica e nomenclatura fundadora nas pretensões épicas do Diálogo das grandezas do Brasil, de Ambrósio Fernandes Brandão e La Argentina y Conquista del Río de la Plata, de Martín del Barco Centenera.

Na sequência, a Arcádia indigenista no Brasil corresponde ao neoclassicismo romântico na Argentina, em uma linha traçada entre Caramuru, de Santa Rita Durão, e Dido y Argia, de Juan Cruz Varela, nos prelúdios da Inconfidência Mineira que serve de eixo central aos poetas Cláudio Manoel da

7. RAMA. Literatura, cultura y sociedad en América Latina. 
Costa, Tomás Antônio Gonzaga, Basílio da Gama, Inácio de Alvarenga Peixoto e Manuel Inácio da Silva Alvarenga.

Durante o momento independentista, o Hino Nacional argentino se impõe com sua retórica conservadora e seu impulso revolucionário, como consequência das aventuras de La lira argentina, em que Vicente López e Planes concorda com Esteban de Luca e Fray Cayetano Rodríguez, enquanto Gonçalves de Magalhães e Gonçalves Dias denunciam o tráfico de escravos e reclamam as propostas políticas de José da Silva Lisboa que encontram seu correlato rioplatense na operação de Mariano Moreno de traduzir El contrato social, de Jean-Jacques Rousseau.

No estreito vínculo entre romantismo e nação convém recuperar a função dos "publicitários" na configuração da literatura nacional: Hipólito da Costa com o Correio Brasiliense, Evaristo da Veiga com a Aurora Fluminense, Juan Bautista Alberdi (Figarillo) com La Moda e Domingo Faustino Sarmiento com El Zonda. Por sua vez, a revista Niterói e a Minerva Brasiliense representam o equivalente do Salão Literário de 1837 em Buenos Aires, cujo vínculo mais aparente é constituído por Juan María Gutiérrez e cujas figuras distintivas - Esteban Echeverría, Marcos Sastre - se situam no contexto do rosismo. Se Gonçalves Dias antecipava a reivindicação dos excluídos, a presença do negro será fundamental nos textos de Fagundes Varela e na origem da gauchesca rioplatense, desde o começo com o mulato montevideano Bartolomé Hidalgo - ou com Juan Gualberto Godoy, como sustenta outra hipótese - até conseguir condição de denuncia direta do regime com Hilario Ascasubi (Aniceto el Gallo).

De sua parte, Manuel José de Lavardén defende o utilitarismo escravagista na Ode al Paraná enquanto intelectual negreiro que exalta a rota da sua mercadoria; no outro extremo os condoreiros Pedro Luis e Castro Alves se horrorizam com "Navio Negreiro". Já fora da poesia e das urgências denunciantes surgem os intelectuais orgânicos da Nação. Crítica e oratória política se combinam em José Bonifácio de Andrada e Silva, tutor do herdeiro imperial Pedro II, e Juan María Gutiérrez, redator da Constituição Nacional e ministro do Governo da Confederação Argentina.

A organização nacional convoca a recuperação ou a invenção de lendas autóctones, com a consequente canonização da obra e do autor: José de Alencar se dedica ao indigenismo romântico na versão tupi (Iracema) e guarani ( $O$ guarani), enquanto a Argentina revisa a figura do gaucho na ensaística sarmientina (Facundo) e na culminação gauchesca de José Hernández (Martín Fierro). A 
literatura "negreira" também encontra seu apogeu, aplicando as variantes do modelo norte-americano de A cabana do Pai Tomas - A escrava Isaura, de Bernardo Guimarães, as nostalgias rosistas em Lucio Victorio e Eduarda Mansilla e o percurso por uma cidade que se moderniza na arquitetura e muda sua fisionomia social em La gran aldea, de Lucio V. López. Na zona suburbana proliferam os bandoleiros: Viriato e Silvino, de Gustavo Barroso, ao mesmo tempo que Juan Moreira e Hormiga Negra, de Eduardo Gutiérrez. Entre a cidade e aquilo que é suburbano se ergue a utopia provinciana do burguês conquistador que, se no Brasil implica o classicismo de Machado de Assis, na Argentina se expande nos excessos de Sarmiento, entre o desequilíbrio pessoal e o rigor literário, e outras combinações possíveis.

Com a Guerra da Triple Aliança impõem-se as repercussões literárias, mesmo em assincronia entre os dois países: se A retirada da Laguna, de Alfredo de Escragnolle Taunay, é contemporânea das cartas que da frente de batalha escreve Lucio Victorio Mansilla, a trilogia de Manuel Gálvez sobre o Paraguai (Los caminos de la muerte, Humaitá e Jornadas de agonía) já se inscreve na extensão e na revisão do conflito, dividindo a década de 1920. A partir das tribunas modernistas que constituirão os jornais se manifesta o maior promotor argentino da guerra, o general Bartolomé Mitre, fundando La Nación como "tribuna de doutrina”, enquanto Rui Barbosa no Brasil orienta também a ênfase oratória voltada para a política.

Chegando ao final do século XIX, as divisas nacionais de "Ordem e progresso" e "Paz e administração" promovem o ensaio positivista e a ficção naturalista no contexto que preveem os marechais brasileiros e o roquismo portenho. É o momento ideal para que se propague o ensaio exaltado com Silvio Romero, Nina Rodrigues e o último Sarmiento, obstinado na condenação em Conflicto y armonía de las razas en América. Mais próximos ao cientificismo sociológico que ao impressionismo racista se mostram Tobías Barreto e Ernesto Quesada, que confluem em uma germanofilia que renova as categorias de pensamento, antes que apareça o cientificismo socializante representado por Joaquim Nabuco e José Ingenieros.

O naturalismo, por sua vez, se especializa em ficção condenatória: Aluísio Azevedo e João Batista de Lacerda mantêm num meio inóspito os mesmos argumentos equívocos de "degeneração" que seus homólogos argentinos: Eugenio Cambaceres, Antonio Argerich e Manuel Podestá. O incerto cientificismo - apesar da condição médica de Argerich e Podestá - se expande em heterodoxia com os "raros" finisseculares: Raúl Pompéia (O Ateneu), Rodolfo Teófilo (Violação, violência), Francisco Sicardi (Libro extraño) e, já entrando no século XX, Atilio 
Chiappori (Borderland). Do lado histórico-social se impõe o sonho da "raça ariana" nas elucubrações de Oliveira Viana e Vicente Fidel López.

As marcas de classe no discurso, se pelo lado novelístico e ensaístico recomendam a prevenção contra os "perigos sociais" (mestiços, emigrantes, anarquistas), no campo da crítica adquirem um confuso matiz republicano, mas se mantêm na ordem dos preconceitos: é assim com Araripe Júnior e Afrânio Peixoto, revisando e rearmando o cânone brasileiro, do mesmo modo que Martín García Mérou submete a escrutínio seus contemporâneos em Libros y autores, antes de se lançar ao primeiro exercício de deferência aos vizinhos - em termos culturais e diplomáticos - plasmado em El Brasil intelectual(1900). São os preâmbulos do modernismo latino-americano que tem suas primeiras manifestações em dois poetas que optam pelas alturas: Fontoura Xavier (plagiado por Darío) em El águila e Leopoldo Lugones com suas iniciais Las montañas del oro.

\section{Segundo momento}

Da crise da Bolsa de Valores até a queda dos governos populistas (1891-1955)

Apogeu e crise do liberalismo, para retomar a nomenclatura balzaquiana: se a Geração de 1880 representava o primeiro termo, a crise de 1890-91 é claramente o outro extremo, cujas consequências literárias fornecem $O$ Encilhamento, de Visconde de Taunay, e La Bolsa, de Julián Martel, obra-chave de um ciclo que se completa com Quilito, de Carlos María Ocantos, e Horas de fiebre, de Severo Villafañe. A dialética se expande: à fase de apogeu e crise se sobrepõe o reverso sinistro da aparência esplendorosa, na forma de relatórios e crônicas que compendiam evidentes denúncias. Enquanto Euclides da Cunha lamenta, em Os sertões (1902), um extermínio que nunca propôs a possibilidade de integração, Juan Bialet Massé revela as falências do modelo liberal-oligárquico em Informe sobre la clase obrera en la Argentina (1904), impondo uma releitura da dialética sarmientina sobre civilização e barbárie.

Os conflitos fronteiriços entre Brasil e Argentina exigem demarcação de limites territoriais (atividade que corre por conta do Barão de Rio Branco e Estanislao Zeballos) e culturais no marco da disputa Campos Salles/Roca, cuja ramificação mais intolerante parece ser a proposta de Gálvez para fomentar uma 
guerra entre Argentina e Brasil, a fim de fortalecer o sentimento nacional (El diario de Gabriel Quiroga, 1910).

O impacto das novas técnicas nas cidades modernizadas pelos liberais promove a aparição dos cronistas cinematográficos: Coelho Neto admite a condição efêmera da atividade no título Vida mundana, Elísio de Carvalho não deixa por menos e o submete à pura sociabilidade vazia do Five o'clock, ao mesmo tempo que Horacio Quiroga transforma essa ocupação em fundamento da profissionalização do escritor ("O esposo de Dorothy Phillips" será o pseudônimo com o qual assina suas colaborações em Caras e Caretas) e Nicolás Olivari instala a prática como um jogo de hábitos vulgares e desleais nos bosquejos contidos em El hombre de la baraja y la puñalada.

Na província, repondo a dialética constante entre centro e periferia, se situam gaúchos e gaúchos judeus: ao rio-grandense José Simões Lopes Neto lhe correspondem as estampas entrerrianas do russo Alberto Gerchunoff. A imigração, atenuada como conflito, é abordada em termos de integração; por isso os comediógrafos da burguesia triunfante (Artur Azevedo e Gregorio de Laferrère) a separam dos seus interesses imediatos. Sobre eles operará a crítica literária, que perto do Centenário se junta à confraria positivista certa de que o método que a move é exato: Taine tem no Cone Sul uma descendência que integra a Capistrano de Abreu, José Veríssimo e Ricardo Rojas, enquanto a literatura contemporânea se inicia em um protorregionalismo que, após o adágio castigat ridendo mores, promove os quadros costumbristas de Franklin Távora e Roberto J. Payró. Descrentes de ambas as tradições - a cientificista e a regional -, os reformistas universitários lançam o manifesto "Para a juventude da América do Sul" e ampliam sua proclamação pela América Latina, de Córdoba ao Rio e São Paulo, passando por Lima, Havana e México.

As consequências mais evidentes da crise econômica, social e cultural serão os maus hábitos de boa parte da população e o empenho para conseguir ordem de qualquer maneira por parte dos governos. É o momento em que se disseminam os cronistas da monstruosidade, encabeçados por Lima Barreto e Elías Castelnuovo, iniciadores de uma série que se atenua nas crônicas urbanas de João do Rio e Enrique Loncán e se exaspera na dramaturgia da cidade hostil com os grotescos de Armando Discépolo que expõem o fracasso do projeto imigratório.

Autores e editores se decidem pela profissionalização: se esta começou no teatro e continuou no jornalismo, como práticas cuja remuneração imediata alentava a dedicação exclusiva, agora será o campo editorial que induzirá 
a seguir este caminho: Monteiro Lobato e a Companhia Nacional Editora terão um sucesso que nem de longe consegue Manuel Gálvez com a Cooperativa Editorial Buenos Aires. Mas o principal impacto mercantil aparece registrado nessa forma galardoada que é o folhetim (O Romance Semanal, O Romance do Dia), que pela temática e recursos, mesmo que não seja através da circulação, pode se comparar com o produto popular em estado puro que é a literatura de cordel.

Tais exercícios ficcionais moralizadores são compreensíveis em um contexto em que a enunciação e a preservação dos valores não apenas se transformaram em algo desejável como também não hesitam em praticar excessos. A organização da direita católica confirma esse ponto com Jackson de Figueiredo e as fundações do Centro Dom Vital e a revista A Ordem (1921), enquanto em Buenos Aires Atilio Dell'Oro Maini cria os Cursos de Cultura Católica e dá forma à revista Criterio (1928). Quando o catolicismo adquire inflexão política, se constitui em estreito nacionalismo e deriva na Ação Integralista Brasileira conduzida por Plínio Salgado, na Liga Republicana de Roberto de Laferrère e Carlos Ibarguren e em uma multidão de associações e jornais de extrema-direita que circulam nas décadas de 1930 e 1940. Alguns dos ultradireitistas tinham se iniciado na vanguarda, que não apenas almejava estes personagens como também a alguns "velhos" escolhidos, como assim o confirmam Graça Aranha (o acadêmico autor de Canaâ), Ricardo Güiraldes (o estranho autor de Xaimaca) e Macedônio Fernández (o impenitente filósofo do Novela de la eterna).

A Semana de Arte Moderna e o martinfierrismo revelam os vínculos entre governos democráticos e abertura estética, além de destacar o impacto das vanguardas europeias na América Latina, ao que é preciso somar a presença de Blaise Cendrars no Brasil e a de Filippo Marinetti na Argentina, antes que os exílios da Guerra Civil espanhola atraiam aos peninsulares para o Rio da Prata e a organização das universidades no Brasil convoque os franceses ao país (Lévi-Strauss, Roger Bastide). Os órgãos renovadores da vanguarda são as revistas: ao paralelo entre Klaxon e Proa se soma o da Revista de Antropofagia Martín Fierro, que se desdobra em tupi com alaúde e gaúcho com viola. Os autores dos manifestos que contêm os programas de renovação se prestam a um paralelo mais exato: Oswald de Andrade e Oliverio Girondo são submetidos a escrutínio por Jorge Schwartz em um livro já clássico (Vanguarda e cosmopolitismo).

Mário de Andrade prefere o papel de rapsodo indigenista, flexionando rumo a um mundo clássico no qual também se inscrevem Nicolás Olivari, inspirado pela Musa de la Mala Pata, e Leopoldo Marechal com seus retornos permanentes 
ao mundo grego. De fato, Macunaíma e Adán Buenosayres também podem ser esboçados como equivalentes: em um caso é o medievalismo - como tantas leituras enfatizaram - e no outro o classicismo para os que encontram acolhida na bacia Amazonas-Iguaçu.

Também, como já apontei, as inflexões da direita encontram espaço no panorama revulsivo promovido pela vanguarda: uma delas é a que conduz da facção do verde-amarelismo ao varguismo, e do nacionalismo ao peronismo: Tristão de Athayde (Alceu de Amoroso Lima) e Cassiano Ricardo junto com Ernesto Palácio e Marechal. Uma segunda inflexão é a que representam Plínio Salgado e Hugo Wast respectivamente, associados a dois animais com forte sentido territorial: "Anta" e Huemul. A terceira permite comparar a Guilherme de Almeida e Julio Irazusta. A eles se somam, com uma militância menos política que estética, os poetas católicos, num arco que se estende entre Festa (Murilo Mendes, Jorge de Lima, Augusto Frederico Schmidt, Cecília Meireles) e Soly Luna (Marechal, Francisco Luis Bernárdez, Ignacio Anzoátegui). Do lado da poesia humanista se destacam Manuel Bandeira e Raúl González Tuñón.

Nesses anos - década de 1930 -, o ensaio sobre a identidade se especializa nos "homens nacionais", entre o "café com leite" e o radicalismo: ao "homem cordial" de Sérgio Buarque de Holanda corresponde o "homem que está só e espera" de Raúl Scalabrini Ortiz. Nos anos que na Argentina correspondem à Década Infame e no Brasil ao Estado Novo, cuja extensão será a inevitável comparação entre Vargas e Perón, o ensaísmo nacional produz textos que serão considerados como a solução para se entenderem os respectivos países: Casa-grande Esenzala, de Gilberto Freyre, eleva o que é regional ao que é nacional da mesma forma que Radiografía de la pampa, de Ezequiel Martínez Estrada, se extasia em determinismos geográficos nefastos. Por sua vez, Paulo Prado prefere traçar um Retrato do Brasil ao mesmo tempo que Eduardo Mallea sintetiza em dois países afrontados sua Historia de una pasión argentina.

A resposta a essas expansões pretensiosamente explicativas se assenta na estética da miséria que desenvolvem tanto o regionalismo nordestino como o grupo portenho de Boedo: Graciliano Ramos (Vidas secas) se situa em assincronia com Juan José Manauta (Las tierras blancas); mais próximos no tempo estão José Lins do Rego com seu ciclo da seca e Joaquín Gómez Bas com Barrio gris; em um arco temporal mais amplo é possível situar a Jorge Amado com a tendência pitoresca do baiano e a Bernardo Verbitsky com sua recaída "villera" ("villa" = "favela"), assim como a Érico Veríssimo e seu realismo sulista junto à fauna "oficinesca" do 
Estado de Roberto Mariani. Mas os cronistas mais precisos da cidade modernizada são Marques Rebelo e Roberto Arlt. Em outro extremo aparecem os cronistas da mansão senhorial, Cornélio Pena e Enrique Larreta e, mais desapegados de ideologias e nostálgicos, os cronistas da casa em decadência, Lúcio Cardoso e Manuel Mujica Láinez. Para que este paralelo não fique como um mero arbítrio especulativo, convoco no traçado do itinerário aos que favoreceram e praticaram intercâmbios e traduções: Newton Freitas e Lidia Besouchet instalando-se em Buenos Aires, e Benjamín de Garay e Raúl Navarro, da Editora Claridad, levando a conhecer, em espanhol, os seus vizinhos e instituindo as versões que ainda hoje circulam dos textos mais identificáveis da literatura brasileira na Argentina.

\section{Terceiro momento}

\section{Desenvolvimentismo, ditadura e Mercosul (1956-2000)}

Depois do populismo varguista-peronista surge um período de revisão, privatização e de reflexão. O fantástico aparece como o primeiro e elementar refúgio ante a imediatez: assim se apresenta nos contos de Clarice Lispector tanto como nos dos acérrimos antiperonistas Julio Cortázar e Silvina Ocampo. Outros autores optam pela ambígua proteção do refinamento: a esse seleto círculo é preciso adicionar o nome de Osman Lins e José Bianco.

No espaço da exibição, o teatro se decide pela renovação cênica: Ariano Suassuna e Osvaldo Dragún são os nomes mais representativos dessa tendência à qual também presta tributos Agustín Cuzzani. A poesia, com maior facilidade para se subtrair ao que é imediato, se decide pelo radicalismo através dos poetas concretos (Haroldo de Campos, Augusto de Campos, Décio Pignatari), os surrealistas e sua proximidade (Aldo Pellegrini, Enrique Molina, Francisco Madariaga, Edgar Bailey, Olga Orozco) e os respectivos órgãos de difusão: a filoprovençal revista Noigandres; as provocativas Qué, Letra y Línea e A partir de cero; a já canônica Poesia Buenos Aires.

Na poesia também se traça uma forma de colaboração frutífera nos dois países, tendo como eixo central música e literatura: Vinicius de Moraes se transforma em letrista de canções enquanto surge a Bossa Nova; Homero Manzi e Enrique Santos Discépolo, dedicados às letras de tango, fornecem fortes condições para que nos anos 1960 apareça Horacio Ferrer. São modos de intervenção direta, 
de criação de um público, de contato imediato com o receptor, que reclamam ajustes correlativos em outros arranjos.

Dessa forma se produz a ressignificação do "compromisso intelectual" que constituiu a militância sartriana de extensas ressonâncias na América Latina. A narrativa e a dramaturgia se impregnam com essa noção: o teatro de João Cabral de Melo Neto tem a mesma vocação denunciante das não ficções de Rodolfo Walsh e a narrativa de Haroldo Conti. A poesia não vacila ante a militância: Ferreira Gullar, Juan Gelman e Paco Urondo são as figuras mais destacadas dessa eleição.

No ensaio socioeconômico se erradicam as tendências impressionistas e são preferidos os enfoques submetidos ao método das ciências humanas. Entre os anos 1950 e 1960 se assiste à troca do desenvolvimentismo pelo dependentismo, de modo que as postulações de Celso Furtado e Raúl Prebisch no marco da CEPAL recebem sua crítica nos textos de Fernando Henrique Cardoso e Theotónio dos Santos no Brasil, enquanto Juan José Sebreli prefere analisar as consequências da economia sobre a sociedade em Buenos Aires, vida cotidiana y alienación. Parte dessa cotidianidade está representada pela música popular, cujo aspecto de protesto, sem chegar a postulados revolucionários, é contudo suficientemente provocativa a ponto de receber a censura do poder, se manifesta nas divergências entre Caetano Veloso e Chico Buarque de Holanda de forma similar à distância que se registra na Argentina entre o rock nacional e o folclore. A MPB e o rock nacional constituirão o cânone musical de cada país a partir dos anos 1960, reeditando o paradoxo estabelecido no campo literário de um cânone apoiado em sua excentricidade. Os grandes autores do momento são excêntricos e canônicos ao mesmo tempo: João Guimarães Rosa e Jorge Luis Borges. Ambos foram evitados pelas luzes do boom latino-americano. Não obstante, no momento da comparação mais próxima, parece inegável que Grande sertão: veredas não pode se comparar aos contos e ensaios de Borges, mas reclama outro romance como contrapartida, e nesse ponto é preciso recorrer ao plano principal do boom e reconhecer o caráter experimental de Rayuela nesse papel.

No aspecto teatral, a resistência política encontra a dramatização mais conveniente nas obras de Augusto Boal e Eduardo Pavlovsky. A crítica, por sua vez, se divide entre a tentação teórica e a incorporação do contexto. A partir da Academia é possível reconhecer as figuras simétricas de Álvaro Lins e Ana María Barrenechea, enquanto no conceito da literatura como prova das relações sociais os nomes que se impõem como criadores de um método que exercitam durante décadas e que mudam o modo de escrever crítica na América Latina são Antonio 
Candido e David Viñas. Essas afirmações locais não evitam, entretanto, a modernização referente aos modelos estrangeiros, praticada por Afrânio Coutinho unido ao new criticism e difundida pela revista Los Librosinstalando-se como tribuna do estruturalismo na Argentina. Mais rara e parcial é a figura do leitor-artista, seja Augusto Meyer, ou seja Borges em sua fase de crítico de textos; e menos massiva em seu cultivo de um método que conduz da filologia à estilística se destaca a prática de Agripino Grieco e Enrique Pezzoni.

Os efeitos do boom como fenômeno mercantil dão a pauta sobre a qual se desenvolve a produção literária dos anos 1960 e os seguintes, que permitirá pensar a possibilidade de integração cultural através de uma iniciativa comercial como o Mercosul. Entre as sinuosidades do boom conseguem um lugar tanto a costumbrista Dona Flor e seus dois maridos, de Jorge Amado, como a vanguardista Rayuela, de Julio Cortázar. Se no campo dos autores centrais são esses nomes os que se destacam, no plano dos laterais do boom aparecem Osman Lins e Manuel Puig. Outra forma de inclusão no mercado, midiatizada pelas empresas jornalísticas, são as misturas de códigos entre o que é verbal e o que é icônico, fornecidas pelas histórias em quadrinhos. Se do lado brasileiro aparece A turma da Mônica, do lado argentino prolifera nos livros de Mafalda e, em ambos os casos, apela para a manejo social dos seus personagens: campanhas de vacinação, prevenção de acidentes e uma infinidade de temas vinculados à infância.

As imagens também contribuem com sua especificidade para a transposição cinematográfica da literatura e da política locais: o Cinema Novo de Glauber Rocha se encontra com o exercício mais socializante da Escola de Santa Fé e o Cine Liberación organizado por Fernando Birri (como consta inclusive na afetuosa evocação que Birri faz de Glauber para o filme de Eryk Rocha, Rocha que voa, em 2000); Nelson Pereira dos Santos, mais preocupado com a restituição de certos aspectos de ordem social que com as investigações rituais de Rocha, tem seu correlato no retrato da classe média urbana que realiza Leopoldo Torre Nilsson. Do rural passou para o urbano, criando um pano de fundo para que se escrevam os romances da cidade sitiada, desde os policiais negros de Rubem Fonseca até os mais rurais de Osvaldo Soriano, sempre com tendência ao grotesco. Em cidades brasileiras encontram acolhida três exilados argentinos: o poeta Néstor Perlongher, o cineasta Héctor Babenco e o romancista Puig, cujo pretexto tropical pode ser encontrado na prolongamento de José Mármol.

A última comparação deve renunciar à literatura e se colocar exclusivamente na órbita mercantil. O título inovador e desconcertante se proclama 
"Autoajuda na língua latina”, e seus guias mais enfáticos e bem-sucedidos (ainda que com uma notória diferença de popularidade, lucros e inclusive expectativas) são Paulo Coelho e Jorge Bucay.

Seguindo o modelo sempre orientador da Biblioteca Ayacucho, que estabeleceu o cânone da literatura latino-americana sob a direção de Ángel Rama, é de se esperar que este projeto se desenvolva com algumas ferramentas que, se não oferecem a vantagem de um controle do método, ao menos apoiam o conjunto através de uma cronologia de fatos locais e mundiais.

\section{Proposal for approaches to a comparative history of Argentinean and Brazilian literatures}

Abstract: The proposal for a comparative history of Argentinian and Brazilian literature as an effective regional integration practice, in a case of Mercosul in which cultural aspects are relegated face of economic and trade policies and strategies to face up world powers as a block, it presents many positive aspects that operate as an incentive to be put into practice. On the one hand, promotes the development of a local comparativism, without the constraints that encourage the comparative literature as a discipline of metropolitan origin. On the other hand, favors the development of an original theory and literary criticism, taken from "the ideas out of place" that usually apply to such proposals. Finally, aims a cultural movement between Argentina and Brazil, which so far remains unpublished and constituted more as an intellectual obligation than in a desirable possibility.

Keywords: Comparative literature, cultural history, literary criticism.

$$
\text { Referências }
$$

BOSI, Alfredo. Historia concisa de la literatura brasileña. México: Fondo de Cultura Económica, 1982.

CANDIDO, Antonio (1969 [1957]). Formação da literatura brasileira. Momentos decisivos. São Paulo: Martins, 1969.

CANDIDO, Antonio. Literatura e sociedade. São Paulo: Ouro sobre Azul, 2000.

FERNÁNDEZ BARAIBAR, Julio. Un solo impulso americano. El MERCOSUL de Perón. Prólogo de Hélio Jaguaribe. Buenos Aires: Fondo Editorial Simón Rodríguez, 2005. 
GUTIÉRREZ GIRARDOT, Rafael (1987). Modernismo. Supuestos históricos y culturales. México: Fondo de Cultura Económica, 1987.

RAMA, Ángel. Literatura, cultura y sociedad en América Latina. Antología, prólogo y notas de Pablo Rocca con la colaboración de Verónica Pérez. Montevideo: Ediciones Trilce, 2006.

RAMA, Ángel. La ciudad letrada. Buenos Aires: Ediciones El Andariego, 2007.

SAID, Edward. Cultura e imperialismo. Barcelona: Anagrama, 1994.

SAID, Edward. Orientalismo. Barcelona: De Bolsillo, 2003.

SCHWARZ, Roberto. As idéias fora do lugar. In: Ao vencedor as batatas. 2. ed. São Paulo: Duas Cidades, 1977. p. 13-28. 